\title{
A construção de projetos terapêuticos: visão de profissionais em dois centros de atenção psicossocial
}

\section{The construction of therapeutic projects: professionals' visions in two psychosocial care centers}

\author{
Elisabete Ferreira Mângia ${ }^{1}$, Jucelena Pietroforte Lopes Vargas Castilho ${ }^{2}$, \\ Velta Regina Eichman Duarte ${ }^{3}$
}

\begin{abstract}
MÂNGIA, E. F.; CASTILHO, J. P. L. V.; DUARTE, V. R. E. A construção de projetos terapêuticos: visão de profissionais em dois centros de atenção psicossocial. Rev. Ter. Ocup. Univ. São Paulo, v. 17, n. 2, p. 87-98, maio/ago., 2006.

RESUMO: A construção de projetos terapêuticos foi estudada a partir da visão de profissionais que atuam em 2 Centros de Atenção Psicossocial (CAPS) na cidade de São Paulo. Este tema tem importância central para a formulação das estratégias, definição de um novo perfil assistencial e organização dos novos serviços de saúde mental. Os cenários de estudo foram os CAPS II Perdizes e CAPS II Mandaqui, do Município de São Paulo. Foram realizadas pesquisa documental e bibliográfica, observação de campo e 8 entrevistas semi-estruturadas com profissionais de diferentes categorias. Buscou-se apreender o processo de concepção e realização dos projetos terapêuticos destinados a usuários com transtornos mentais severos, bem como identificar as dificuldades e limites apontados por esses profissionais para a sua execução. Foram observadas diferenças na estrutura de atendimento e na execução do projeto terapêutico nas duas instituições. As dificuldades e limites para a execução do projeto terapêutico são semelhantes nos dois serviços.
\end{abstract}

DESCRITORES: Serviços de saúde mental. Planos e Programas de Saúde. Prática profissional. Terapia ocupacional.

${ }^{1}$ Prof. Dra. do Departamento de Fisioterapia, Fonoaudiologia e Terapia Ocupacional da FMUSP.

${ }^{2}$ Especialista em Saúde Mental e psicóloga do CAPSII-Perdizes.

${ }^{3}$ Especialista em Saúde Mental e enfermeira do CAPSII-Mandaqui.

Endereço para correspondência: Departamento de Fisioterapia, Fonoaudiologia e Terapia Ocupacional da FMUSP. Rua Cipotânea, 51, Cidade Universitária, São Paulo, SP, CEP: 05360-160. 
MÂNGIA, E. F. et al. A construção de projetos terapêuticos. Rev. Ter. Ocup. Univ. São Paulo, v. 17, n. 2, p. 87-98, maio/ago., 2006.

\section{INTRODUÇÃO}

$\mathrm{O}$ cenário de estruturação da nova política de saúde mental, que no Brasil tem início no contexto da implantação do Sistema Único de Saúde, passa por um momento decisivo. A redução de leitos psiquiátricos, o maior controle sobre as internações, a organização de rede de serviços baseados na comunidade e especialmente o reconhecimento dos direitos de cidadania das pessoas com transtornos mentais, compõem o perfil dessa nova forma de compreender e tratar os transtornos mentais. Nas últimas décadas, vem acontecendo um processo de permanente construção desse novo ideal de cuidado, que ainda depende da estruturação de modelos assistenciais e estratégias técnicas orientadas por novos valores.

A significativa ampliação da implantação de serviços na comunidade e especialmente, a abertura dos Centros de Atenção Psicossocial (CAPS), como modalidade de serviço central ao novo modelo, prescindem ainda da consolidação de saberes e práticas que possam distanciar-se do modelo anterior, que adotava como medida terapêutica principal a necessária internação dos casos graves em instituições fechadas e estava centrado na doença e na remissão dos sintomas.

Para isso, há um complexo conjunto de desafios que estão sendo pouco a pouco enfrentados. Dentre eles merecem destaque a formação de profissionais de saúde mental orientados por esse novo modelo e suas estratégias, e a organização inovadora dos serviços de saúde mental que permita o exercício de uma abordagem integral da pessoa em seu contexto real de vida e de acordo com as suas necessidades. Além disso, há cada vez mais a necessidade de comprometer os gestores municipais de saúde sobre a importância do desenvolvimento de políticas municipais de saúde mental e a ampliação da participação de usuários, familiares, trabalhadores e a comunidade em geral no controle social, estratégia fundamental para garantir a manutenção, continuidade e ampliação, com qualidade, das novas modalidades assistenciais que vem sendo implementadas em nosso país e que ainda enfrentam vários obstáculos para sua consolidação.

\section{A criação de serviços na comunidade}

As normativas adotadas pelo Ministério da Saúde para regulamentar as novas modalidades de serviços que compõem a rede de saúde metal são recentes e podem ser compreendidas como uma proposta/desafio, uma vez que, se por um lado, contemplam elementos testados em experiências pioneiras e inovadoras e são resultado de um consenso técnico articulado às novas tendências internacionais de organização de serviços, por outro, precederam a implantação da maior parte das experiências municipais, colocando-se como um objetivo a ser conquistado.

Se tomarmos as normativas propostas para os CAPS, (criados pela portaria 224/92 e melhor definidos na Portaria 366 de 2002), nos deparamos com uma complexa definição sobre organização e prática de serviço que ainda poucos no Brasil estão capacitados para atingir, tanto do ponto de vista da cultura técnica, como do ponto de vista da organização do serviço e de seu processo de trabalho (BRASIL, 1992, 2002).

Diferenciados em CAPS I, II e III, de acordo com o território de abrangência, número de pacientes atendidos, dimensões da equipe e horário de funcionamento, CAPS AD para atendimento de pacientes com transtornos decorrentes do uso e dependência de substâncias psicoativas, e CAPSi para atendimentos a crianças e adolescentes, são definidos como serviços de saúde mental públicos, comunitários e ambulatoriais de atenção diária, destinados prioritariamente ao atendimento de pacientes com transtornos mentais severos e persistentes em sua área territorial, que oferecem três modalidades de tratamento (intensivo, semi-intensivo e não-intensivo) Devendo funcionar em área física específica e independente.

São atribuições dos CAPS:

“a - responsabilizar-se, sob coordenação do gestor local, pela organização da demanda e da rede de cuidados em saúde mental no âmbito do seu território;

$b$ - possuir capacidade técnica para desempenhar o papel de regulador da porta de entrada da rede assistencial no âmbito do seu território elou do módulo assistencial, definido na Norma Operacional de Assistência à Saúde (NOAS), de acordo com a determinação do gestor local;

c - coordenar, por delegação do gestor local, as atividades de supervisão de unidades hospitalares psiquiátricas no âmbito do seu território;

$d$-supervisionar e capacitar as equipes de atenção básica, serviços e programas de saúde mental no âmbito do seu território elou do módulo assistencial;

$e$ - realizar, e manter atualizado, o cadastramento dos pacientes que utilizam medicamentos essenciais para a área de saúde mental regulamentados pela Portarial GM/MS n ${ }^{\circ} .1077$ de 24 de agosto de 1999 e medicamentos excepcionais, regulamentados pela Portaria/SAS/MS $n^{o}$. 341 de 22 de agosto de 2001, dentro de sua área 
assistencial;

$f$ - funcionar no período de 08 às 18 horas, em 02 (dois) turnos, durante os cinco dias úteis da semana; (BRASIL, 2002).

Para os CAPs III essas atribuições incluem também o acolhimento noturno, nos feriados e finais de semana, com no máximo 05 (cinco) leitos, para eventual repouso e/ou observação; estar referenciado a um serviço de atendimento de urgência/emergência geral de sua região, que fará o suporte de atenção médica.

A assistência prestada ao paciente no CAPS inclui ainda as seguintes atividades:

"a - atendimento individual (medicamentoso, psicoterápico, de orientação); $b$ - atendimento em grupos (psicoterapia, grupo operativo, atividades de suporte social); c - atendimento em oficinas terapêuticas executadas por profissional de nível superior ou nível médio; $d$-visitas domiciliares; $e$ - atendimento à família; $f$ - atividades comunitárias enfocando a integração do paciente na comunidade e sua inserção familiar e social". (BRASIL, 2002)

Nesses serviços, a atenção deve estar centrada no acolhimento, no vínculo entre trabalhadores e usuários, na participação da família, e na responsabilidade de cada membro da equipe no desenvolvimento de projetos terapêuticos. Estes devem ser individualizados e incluir a participação do usuário, respeitando suas escolhas e limites, visando à inserção social e a melhor qualidade de vida.

\begin{abstract}
"Os projetos terapêuticos dos CAPS serão singulares, respeitando-se diferenças regionais, contribuições técnicas dos integrantes de sua equipe, iniciativas locais de familiares e usuários e articulações intersetoriais que potencializem suas ações. Os CAPS deverão obedecer a alguns princípios básicos: devem se responsabilizar pelo acolhimento de 100\% da demanda dos portadores de transtornos severos de seu território, garantindo a presença de profissional responsável durante todo o período de funcionamento da unidade (plantão técnico) e criar uma ambiência terapêutica acolhedora no serviço que possa incluir pacientes muito desestruturados que não consigam acompanhar as atividades estruturadas da unidade. Devem ainda trabalhar com a idéia de gerenciamento de casos, personalizando o projeto de cada paciente na unidade e fora dela e desenvolver atividades para a permanência diária no serviço. O CAPS deve considerar o cuidado intra-, inter- e transubjetivo, articulando recursos de natureza clínica, incluindo medicamentos, de moradia, de trabalho, de lazer, de previdência e outros, através do cuidado clínico oportuno e programas de reabilitação psicossocial" (BRASIL, 2002a).
\end{abstract}

Nessa perspectiva, e, especialmente a partir do consenso sobre a importância da participação e protagonismo dos usuários e familiares na produção e promoção da saúde, se inova também a concepção sobre a construção de projetos terapêuticos. O projeto terapêutico deve ser elaborado e executado com a participação de toda a equipe e dos próprios usuários, ser flexível e ter metas claras estabelecidas, conforme a avaliação dos resultados alcançados. Deve ter como objetivos, o aumento do conhecimento do paciente sobre os seus problemas, a sua autonomia afetiva, material e social, e o seu relacionamento social e político. (SARACENO et al., 2001).

Mângia (2002) propõe como eixos orientadores a serem considerados no desenvolvimento de projetos terapêuticos:

- a centralidade da ação na pessoa;

- a relação de parceria terapeuta-cliente;

- o deslocamento do lócus da ação da instituição para o território e para as situações da vida real;

- a ênfase no sujeito em seu contexto;

- a construção compartilhada do projeto terapêutico com metas dotadas de sentido para a continuidade da vida do usuário;

- o estabelecimento de um contrato de trabalho com percursos a serem desenvolvidos em um tempo predeterminado;

- a utilização de avaliações periódicas conjuntas para redirecionamento do projeto.

Saraceno (2005) nos alerta sobre o risco de que as ações que são executadas nos serviços substitutivos se limitem a reproduzir técnicas isoladas e acabem por perder sentido e resultem na fragmentação dos serviços e dos usuários. As intervenções muitas vezes são pensadas de forma isolada sem a participação da equipe, do paciente e da família.

"Para evitar a fragmentação do cuidado dever-se-ia operar em outro formato do modelo assistencial, comandado por um processo de trabalho cuidador, que oriente esse percurso. Quando isso não existe, o usuário faz o seu próprio caminhar pelas redes de serviços, induzindo consumo de procedimentos. Essa prática é altamente perversa, podendo levar a erros diagnósticos, acessos negados, procedimentos mais onerosos e não efetividade do cuidado. Muitas vezes, só o usuário consegue recuperar a história da sua peregrinação sendo o seu próprio "fio condutor" (MALTA et al., 2004).

"O cuidar de uma pessoa" significa construir como plano de atuação um projeto terapêutico "que implique a existência do sujeito para além da remissão do sintoma". Esse projeto se faz com a reconstrução e apropriação 
MÂNGIA, E. F. et al. A construção de projetos terapêuticos. Rev. Ter. Ocup. Univ. São Paulo, v. 17, n. 2, p. 87-98, maio/ago., 2006.

constantes da história de vida de cada um centralizado na pessoa, ao mesmo tempo "constituído de estratégias até óbvias, artesanais e de estratégias complexas, de longo percurso, que trazem a tona as diferentes dimensões de cada sujeito, de suas relações familiares, sociais, de vizinhança, de sua subjetividade." (CECÍLIO, 2001). Tratase de uma ação que não se limita ao espaço físico da instituição, podendo acontecer no âmbito do próprio serviço, nos espaços de vida, de circulação, e de sociabilidade do sujeito.

Segundo Mângia (2002), projetos terapêuticos que possam ser continuamente avaliados conjuntamente e redefinidos na medida das necessidades de cada momento devem constituir a diretriz central dos serviços substitutivos.

\section{Apresentação do estudo}

Ao nos depararmos com a realidade dos serviços, muitas são as questões que emergem sobre a lógica que vem sendo aplicada na sua organização e na atenção direta aos usuários, e parece evidente que boa parte dos profissionais que atuam em saúde mental, além de desconhecerem as diretrizes da atual política de saúde mental, também estão distantes de uma concepção mais criteriosa sobre a construção de projetos terapêuticos.

Diante desse cenário, este estudo visou conhecer como e a partir de quais critérios os profissionais constroem e implementam projetos terapêuticos, além de identificar as dificuldades e obstáculos presentes nesse processo, especialmente aquelas vinculadas à organização dos novos serviços de saúde mental.

O estudo foi realizado nos CAPS II Perdizes e CAPS II Mandaqui, do Município de São Paulo, nos meses de abril e maio de 2006 e utilizou diferentes recursos para a obtenção dos dados: consulta a publicações relativas ao tema, análise documental, observação de campo e realização de entrevistas semi-estruturadas com quatro profissionais de nível universitário de cada CAPS.

Tratou-se de um estudo descritivo, com abordagem qualitativa (MINAYO et al., 2004). A organização dos dados das entrevistas foi apoiada no procedimento metodológico da "Análise da Enunciação" (AE), elaborada por Bardin (2000). As entrevistas foram gravadas, transcritas e estudadas (BARDIN, 2000). Foram estabelecidas as categorias de análise, combinando os objetivos propostos pela investigação aos conteúdos expressos nas entrevistas. Para cada categoria, foi elaborada a análise contendo os discursos explícitos, as diferentes posições dos atores e a análise propriamente dita, procurando estabelecer um diálogo do que foi encontrado com o referencial teórico adotado pelas pesquisadoras.

O material coletado por meio da observação do campo contribuiu para elaborar a apresentação dos serviços estudados, e para a análise dos dados coletados.

Foi desenvolvido no contexto do IV Curso de Especialização em Saúde Mental da Escola de Enfermagem da USP e aprovado pelos Comitês de Ética e Pesquisa da Escola de Enfermagem da USP (processo 543/2006 - CEPEEUSP) e da Secretaria Municipal de Saúde de São Paulo (processo 048/2006/parecer 078/06).

\section{Cenário do estudo}

\section{O CAPS II Perdizes}

Está localizado na região oeste do Município de São Paulo sob responsabilidade da Coordenadoria de Saúde Lapa-Pinheiros e tem como área de abrangência os bairros de Perdizes, Pacaembu, Barra Funda Pompéia e Sumaré, com uma população estimada em 263.181 habitantes ${ }^{(1)}$.

A região conta com equipamentos de saúde organizados em redes de atenção regionalizada e hierarquizada, sendo que a rede referenciada a este serviço é composta por: 1 CAPS infantil, 1 CAPS álcoole drogas, 1 Centro de Referência e Saúde do Trabalhador, 3 Unidades Básicas de Saúde, sendo uma de apoio, com equipe mínima de saúde mental, 1 Centro de Referência para tratamento da AIDS, 1 Centro de Convivência, 1 Ambulatório de Especialidades, 1 Centro Especializado em Odontologia, 1 Pronto Socorro Municipal.

Implantado em 1972, como ambulatório de saúde mental, passou em 1992 a funcionar como CAPS. Em 2001, foi municipalizado e ainda mantém o ambulatório. Atende adultos com transtornos mentais severos e persistentes (psicóticos e neuróticos graves), em regime de tratamentos intensivo, semi-intensivo e não intensivo com desenvolvimento de projetos de reinserção social e reabilitação psicossocial. Em abril de 2006, possuía 632 pacientes cadastrados, sendo 517 em regime não intensivo, $45 \mathrm{em}$ regime intensivo, e $70 \mathrm{em}$ regime semi-intensivo.

Funciona em prédio independente das 7 às 18 horas, de segunda à sexta-feira. Conta com equipe multiprofissional composta por 5 psicólogos, 1 terapeuta ocupacional, 2 assistentes sociais, 2 enfermeiros, 5 auxiliares de enfermagem e 5 psiquiatras (um deles coordena a unidade), 1 farmacêutico, além de profissionais de apoio administrativo, de atendimento à farmácia e à recepção. O serviço de segurança e de limpeza

\footnotetext{
(1) Dados do SEADE de 2004.
} 
é terceirizado, mas, como esses profissionais são estáveis e conhecem os usuários, muitas vezes auxiliam a equipe multiprofissional.

O serviço possui comissão de ensino e pesquisa, e recebe estagiários da Escola de Enfermagem da Universidade de São Paulo, e visitas quinzenais de alunos da graduação de Psicologia da Universidade Paulistana.

Atende pessoas residentes em sua área de abrangência, realizando pronto atendimento e acolhimento em regime de "porta aberta", sem lista de espera. As pessoas que procuram o serviço vêm encaminhadas das Unidades Básicas de Saúde da região, de outras instituições de saúde, de consultas particulares, ou chegam espontaneamente sozinhos, ou trazidos por familiares.

\section{OCAPS II Mandaqui}

Está localizado na região norte do Município de São Paulo, próximo ao Complexo Hospitalar do Mandaqui e tem como área de abrangência os bairros de Santana, Mandaqui, e Tucuruvi, com população estimada de 318.282 habitantes. A região conta com 1 CAPS Infantil, 1 Centro de Referência para o tratamento da AIDS, 1 para Álcool e Drogas e 7 Unidades Básicas de Saúde, sendo que 3 delas oferecem atendimento psiquiátrico.

Inaugurado em 1977 como Ambulatório de Saúde Mental, passou a funcionar como CAPS em 2001. Atende adultos com transtornos mentais graves, em regime de tratamentos intensivo, semi-intensivo e não intensivo. Funciona em prédio independente das 7 às 18 horas, de segunda à sexta-feira. Em abril de 2006, atendia em média, 350 usuários por mês,

A equipe multiprofissional é composta por 4 psicólogos, 3 terapeutas ocupacionais (uma delas coordena a unidade), 2 assistentes sociais, 2 enfermeiros, 6 auxiliares de enfermagem e 1 psiquiatra, além de profissionais de apoio administrativo, de atendimento à farmácia e à recepção. Os serviços de segurança e de limpeza, embora terceirizados, têm profissionais que se mantêm estáveis na unidade, o que possibilita a convivência de alguns deles com os usuários.

$\mathrm{Na}$ época do estudo, o CAPS recebia estagiários da graduação da Escola de Enfermagem da USP, desenvolvia também, em conjunto com o Centro de Convivência e Cultura (CECCO) Jaçanã/Tremembé, programa de aprimoramento profissional.

Funciona de acordo com a diretriz de "porta aberta", com acolhimento, sem lista de espera. As pessoas que chegam ao atendimento vêm do Pronto Socorro do Complexo Hospitalar do Mandaqui, dos hospitais psiquiátricos, das Unidades Básicas de Saúde, de outras instituições de saúde, de consultórios particulares, ou buscam o serviço espontaneamente.

\section{Dinâmica e funcionamento dos serviços}

Os 2 serviços oferecem: atendimento individual ou em grupo (psicoterapia, escuta, terapia ocupacional, orientação à família, orientação sobre benefícios), atividades em grupos ou oficinas (esportivas, artísticas, culturais, de lazer, de trabalho) e visitas domiciliares. O termo oficina é utilizado pelos serviços, para designar o trabalho em grupo mais voltado à convivência e à inserção social, do que ao tratamento clínico.

As atividades coletivas geralmente são coordenadas por um profissional e podem contar com a participação de outros profissionais.

Os serviços realizam assembléias mensais no CAPS II Perdizes, e semanais no CAPS II Mandaqui, que são reuniões abertas para discussões, reclamações e sugestões sobre o funcionamento do serviço, visando aprimorar o atendimento. Nelas, a participação de funcionários, usuários, familiares, membros da comunidade é incentivada.

Os serviços realizam também, reunião semanal da equipe técnica, para a discussão de aspectos da organização do trabalho e dos projetos terapêuticos dos usuários. Quando necessário, são realizadas reuniões entre os profissionais que assumem responsabilidade direta sobre a condução dos projetos terapêuticos dos usuários.

O CAPS II Mandaqui realiza, antes da reunião técnica, uma reunião administrativa com todos os funcionários da unidade, para divulgar informações e orientações procedentes da Coordenação de saúde e Supervisão da região, da coordenação da unidade e de outros serviços e instituições e discutir problemas, novos planos de trabalho e parcerias, relacionados ao funcionamento do serviço. No CAPS II Perdizes, estes aspectos são abordados na reunião técnica semanal e há 1 reunião mensal com todos os funcionários.

O CAPS II Mandaqui possui um Conselho Gestor, que se reúne mensalmente, composto por funcionários, usuários, familiares e membros da comunidade. O CAPS II Perdizes, ainda não havia implantado seu Conselho Gestor.

O CAPS II Perdizes conta, desde 1994, com uma associação sem fins lucrativos, composta por familiares, usuários, profissionais e pessoas da comunidade, e tem por objetivo, contribuir para a reabilitação dos usuários e estabelecer parcerias em projetos sociais.

\section{DISCUSSÃO}

\section{Construção do Projeto Terapêutico}

De um modo geral, as entrevistas evidenciaram alguns 
MÂNGIA, E. F. et al. A construção de projetos terapêuticos. Rev. Ter. Ocup. Univ. São Paulo, v. 17, n. 2, p. 87-98, maio/ago., 2006.

aspectos comuns e algumas diferenças em relação à construção do projeto terapêutico nos dois serviços. Entre os aspectos comuns, salientamos que a construção do projeto terapêutico não é formalizada e se inicia no acolhimento, quando é dado o primeiro direcionamento ao atendimento. Posteriormente, é discutida nas reuniões semanais da equipe e, também, de modo informal, pelos profissionais mais envolvidos no atendimento ao usuário.

$\mathrm{Na}$ construção do projeto terapêutico pensa-se, em geral, nas necessidades, interesses e habilidades do usuário e no que ele poderia usufruir no CAPS. O projeto terapêutico deve ter sentido para o usuário e ser adequado ao seu contexto e momento de vida. Em ambos os serviços, a proposição inicial do projeto terapêutico é feita, em geral, pelo profissional que atendeu o usuário no acolhimento. Muitas vezes esse mesmo profissional acompanha a execução do projeto terapêutico e, gradativamente, o usuário é incluído nesta elaboração, podendo escolher e experimentar algumas atividades, e tratar de assuntos que vão de encontro às suas necessidades.

Nota-se, também, a preocupação dos profissionais em estabelecer um vínculo com o usuário e inserí-lo no tratamento, tornando-o co-responsável pelo projeto terapêutico. Os profissionais consideram importante criar um campo de confiança, de credibilidade, de validação do relato do usuário, e sustentar o seu projeto de vida. Esse ponto de vista da equipe multiprofissional se evidencia nas entrevistas, nas seguintes opiniões:

“... a gente pode se aproximar dessa pessoa para tentar descobrir algum caminho para seguir com ele".

“... é um projeto que tem que ser construído coletivamente, na parceria com o usuário, e com o familiar, muitas vezes. (...) É poder dar a essa família e a esse usuário a possibilidade de discutir junto".

. "Eu acho importante que ele possa se sentir coresponsável pelo processo de tratamento dele, responsável pelas escolhas que ele vai fazendo (...)... é um exercício de autonomia, de apropriação, e de responsabilização mesmo".

Embora, a família seja considerada uma aliada e incluída no projeto terapêutico, observa-se que, algumas vezes, o contexto familiar é considerado prejudicial ao usuário ou a família tende a tomar decisões opostas às recomendadas pela equipe, como por exemplo, a internação.

"Às vezes a família não facilita muito Em alguns casos a família atropela a gente, e eles têm lá as razões deles, que muitas vezes a gente também tem que levar em consideração. Em algumas famílias em que a situação é difícil e a internação é algo que é possível".

Alguns exemplos de projetos terapêuticos que apresentaram boas respostas por parte dos usuários, foram relacionados à reconstrução da história de vida.

Embora não haja consenso sobre os períodos em que o projeto terapêutico deve ser avaliado e reformulado, a periodicidade depende muito da impressão da equipe sobre os resultados do processo. No decorrer da execução do projeto terapêutico, podem ocorrer mudanças de objetivos, decorrentes do próprio processo de vida do usuário. Percebese também, que há um tempo próprio para que os objetivos traçados no projeto terapêutico sejam alcançados pelo usuário.

Destacam-se dois objetivos centrais na construção dos projetos terapêuticos: evitar a internação e reintegrar socialmente o usuário.

Os serviços oferecem, além do tratamento medicamentoso, atendimento individual, grupos terapêuticos, oficinas terapêuticas e, posteriormente, com a melhora do usuário, as oficinas de trabalho. Os profissionais referem que têm a liberdade para criar grupos, de acordo com as suas habilidades e interesses, podendo oferecê-los ao usuário conforme as necessidades destes. Este aspecto pode ser observado nas entrevistas:

“... a gente tem a liberdade de criar em cada Unidade, de acordo até com a habilidade dos próprios profissionais, do que cada um realmente faz bem, o que de melhor pode oferecer, o programa vai ser montado em cima disso. Tanto das necessidades dos pacientes como da capacitação profissional de quem está na Unidade".

Para a execução do trabalho e construção do projeto terapêutico, os profissionais utilizam vários referenciais teóricos, sem a predominância de nenhum deles. Percebe-se que ocorre a combinação entre referenciais a partir de dois eixos principais: o da formação técnica específica dos profissionais e o das diretrizes do SUS para a saúde mental.

Os profissionais citaram com freqüência " $a$ desinstitucionalização, a Portaria CAPS, a clínica centrada no cliente, a visão holística do paciente, e diretrizes da saúde pública". Observou-se grande dispersão na definição de conceitos e estratégias teóricas utilizadas, embora apareçam alguns eixos comuns das políticas públicas, a idéia da reforma e da rede de serviços substitutivos. A psicanálise foi destacada por alguns entrevistados, como sendo um referencial importante e que permeia as suas atividades. De um modo geral, é possível afirmar que as diretrizes do SUS e os referenciais do campo da reabilitação psicossocial estão sendo, gradativamente, incorporados à prática diária dos profissionais. 
Em relação à construção dos projetos terapêuticos, há diferenças entre os dois serviços quanto à inclusão social, à busca ativa e à referência técnica.

\section{Inclusão Social}

O CAPS-II Perdizes possui alguns usuários que habitam em pensões, albergues e moradores de rua e muitos não têm a referência da família. Isso pode estar relacionado à localização da instituição na região centro-oeste da cidade de São Paulo, próximo ao Elevado Costa e Silva. Está presente na elaboração dos projetos terapêuticos, a idéia da inclusão social, da busca de moradia, de benefícios e a necessidade de se encontrar ou aproximar a família do usuário.

“... essa questão da inclusão social, por esta característica aqui do CAPS que é ter muito morador de rua, (...) essa vertente da inclusão social é muito forte, está muito presente”.

"... encontrar a família, trabalhar com a família a aceitação do usuário, ou incluir o paciente como membro da família, ou conseguir benefício e o paciente conseguir alugar uma vaga de pensão, e aí a gente consegue tratar”.

Já no CAPS-II Mandaqui, esses aspectos não foram destacados e supomos que a maioria dos usuários atendidos more com a família e, portanto, a equipe se defronte menos com a necessidade de moradia e benefícios.

\section{Busca Ativa}

A busca ativa consiste no compromisso dos serviços em responsabilizar-se pelo usuário, que pela própria condição de vulnerabilidade psicológica ou social, tem dificuldade em freqüentar o serviço regularmente. Visa restabelecer o contato com o usuário em seu próprio território, para dar continuidade ao tratamento. No CAPSII Perdizes, ela é realizada com usuários que apresentam dificuldades para se integrarem ao serviço; já o CAPS-II Mandaqui, não desenvolve essa atividade rotineiramente.

As opiniões a seguir representam essa característica:

“... a gente não está afeito a ir atrás do paciente, a buscar, saber por que ele não está se tratando...”.

“... Olha, é a nossa grande dificuldade de pensar.. nisso... porque não temos pernas para poder sair. É algo que a gente está tentando conquistar aqui dentro, é de estar saindo do CAPS e tentar ir ao encontro dessas pessoas, mas ainda não conseguimos construir isso. Alguns casos a gente consegue ir, outros não, mas é um número pequeno, dá para você contar nos dedos."

\section{Referência Técnica}

A referência técnica define um tipo de processo de trabalho no qual o profissional (ou um grupo de profissionais) assume a responsabilização diferenciada sobre o usuário atendido, em que cabe ao técnico estabelecer com usuário, de forma mais próxima e intensiva, as negociações, encaminhamentos e alterações do projeto terapêutico.

A diferença observada entre os dois serviços é que, no CAPS II Perdizes, a referência técnica é formalizada e se constitui como parte da construção do projeto terapêutico, embora isso não ocorra com todos os usuários. A equipe elege um representante para acompanhar mais intensivamente o usuário e este, também pode escolher um profissional com quem tenha um bom vínculo e que possa desempenhar esse papel.

“Em alguns momentos, a gente tira uma pessoa de referência para o paciente. Nem sempre isso acontece. Em alguns momentos a gente sente necessidade. $O$ paciente está mais desagregado, necessita de uma pessoa próxima dele. Então, isso também faz parte aqui dessa idéia de como a gente aborda e acolhe o paciente. (...) a pessoa vai para uma referência, que é aquele que chega lá e faz um trabalho próximo do paciente...".

No CAPS II Mandaqui, percebemos que esse processo não ocorre, e o usuário é referenciado apenas nas atividades que participa. Nota-se que essa característica dificulta as ações da equipe, pois o trabalho se torna fragmentado.

"... ele não fica com a referência de uma pessoa, ele fica com a referência de oficinas...”.

“... como você constrói o projeto terapêutico compartilhado com o usuário e com a equipe, sem ter a intermediação da referência técnica? (...) a referência técnica não é para dar trabalho, é para facilitar o trabalho”.

“... quando não está formalizado, você acha que eu estou procurando, eu acho que você está procurando; nós duas achamos que quem está procurando é a outra, e de fato... daí tem muito mais escape. Você perde muito mais"(2). 
MÂNGIA, E. F. et al. A construção de projetos terapêuticos. Rev. Ter. Ocup. Univ. São Paulo, v. 17, n. 2, p. 87-98, maio/ago., 2006.

As opiniões obtidas nas entrevistas mostraram realidades diferentes na construção do projeto terapêutico nos dois CAPS, que nos levaram a refletir sobre propostas que possam contribuir para a construção mais consistente de projetos terapêuticos.

$\mathrm{O}$ acolhimento foi citado como o primeiro atendimento que o usuário recebe quando chega ao serviço. Observase que o conceito de acolhimento ainda é bastante restrito a ponto de ser usado como sinônimo de triagem e prontoatendimento. Pensamos que o acolhimento deveria ser o eixo central do cuidado cotidiano, uma função fundamental constante, que não se limita ao momento de entrada e recepção do paciente.

Em nossa opinião, o acolhimento deve ser compreendido como uma atitude que se estende durante todo o tratamento, não se restringindo aos primeiros atendimentos. A equipe que adota como estratégia o acolhimento coloca-se disponível, flexível, e se responsabiliza pelas necessidades apresentadas pelos usuários, sendo muitas vezes, levada a enfrentar desafios em relação aos problemas que vão surgindo durante o processo. Essa estratégia de acolhimento favorece a construção de vínculos, a responsabilização dos profissionais pelo acompanhamento da clientela e implica na organização do serviço centrada no usuário e em suas necessidades.

A diretriz do acolhimento deve compor a pauta das reuniões técnicas, permitindo "reflexões sobre o processo saúde-doença e o tratamento, cujo foco não deve se restringir aos sintomas, mas a todas as implicações envolvidas na vida do sujeito..." (MÂNGIA et al., 2002, p.17).

Embora os profissionais afirmem que o projeto terapêutico deve ser elaborado com a participação do usuário, de um modo geral, nos dois serviços se percebe que a equipe assume uma postura mais diretiva em aspectos que poderiam ser elaborados conjuntamente.

O critério avaliativo que os profissionais estabelecem para considerar a gravidade da pessoa que procura o atendimento e introduzi-la nos serviços, não foi citado nas entrevistas, o que pressupõe que não haja homogeneidade na decisão de ingresso dos usuários e nos encaminhamentos realizados. A proposta inicial do projeto terapêutico também pode variar conforme o profissional que faz o acolhimento. Há a tendência à construção de respostas rápidas que tentam enquadrar o usuário na oferta do serviço.

Em apenas uma entrevista encontramos a concepção sobre a necessidade do profissional em ter "abertura para não determinar, não se colocar nesse lugar de poder".

Embora a importância da construção de vínculo entre o profissional e o usuário tenha sido referida, não foi possível perceber claramente de que forma isso acontece.

Ressaltamos, mais uma vez, a importância do acolhimento "que respeita a singularidade, dá voz, e valida o usuário enquanto cidadão e sujeito de direitos", e que se preocupa "com o respeito às diferenças, a tolerância, o acesso, potencializa a confiança, a cooperação, a iniciativa e a criatividade" (MÂNGIA et al., 2002).

É importante que os profissionais considerem a relevância da criação de um campo de confiança, credibilidade e validação do relato do usuário, e da sustentação de projetos de vida. A participação efetiva do usuário é fundamental para o processo de construção do projeto terapêutico. O usuário deve tornar-se um aliado na busca de soluções para os seus problemas de saúde, no contexto da saúde como direito. (ARANHA e SILVA; FONSECA, 2003).

O conhecimento e apropriação sobre sua história de vida tornam o sujeito mais consciente das contradições, conflitos e necessidades. A escuta e o conhecimento sobre a realidade de vida do paciente - onde mora, com quem, do que se alimenta, com quanto dinheiro vive, quem está à sua volta, onde trabalha, etc. - favorece a construção desse processo. No curso do desenvolvimento de cada projeto terapêutico novas necessidades se manifestarão, assim como a capacidade de compreensão e expressão das próprias exigências e expectativas de vida por parte do sujeito, e o serviço deve estar preparado para responder com flexibilidade a isso (DELL'ACQUA; MEZZINA, 2005).

As entrevistas demonstraram que a construção do projeto terapêutico está voltada às necessidades, interesses e habilidades dos usuários, de acordo com o que ele poderia usufruir no CAPS. Percebe-se que existe uma adequação das necessidades do usuário ao que o serviço oferece. Em geral, está muito presente a idéia de construir o projeto terapêutico do usuário a partir das atividades que os serviços oferecem. Dessa forma, o usuário que tem interesses ou necessidades diferentes daquelas oferecidas pelo serviço acaba por não se encaixar nesse contexto (DELL'ACQUA; MEZZINA, 2005).

Os objetivos de evitar a internação e inclusão social, e não só a remissão dos sintomas, estão incorporados ao repertório dos técnicos dos dois serviços, embora os meios para atingi-los ainda sejam escassos. A valorização da

(2) Isso foi dito em relação à tentativa explicar que existe a fragmentação da equipe. 
participação do usuário em outros tratamentos que compõem o projeto terapêutico, também relativiza a importância da abordagem centralizada no tratamento medicamentoso.

A referência técnica foi apontada como uma forma de facilitar o trabalho da equipe. Entendemos que ela é um ponto importante na concepção do processo de trabalho dos serviços de saúde mental quando a equipe distribui, entre os seus membros, uma responsabilização que efetivamente deve ser assumida. Dessa forma, há a necessidade do desenvolvimento de uma nova postura dos profissionais, na medida em que estes mudam o seu perfil de trabalho, $\mathrm{e}$ não se ocupam mais só de uma parte do atendimento, mas se responsabilizam em fazer a gestão do caso de forma integral. Essa estratégia pode melhorar a qualidade do trabalho da equipe, evitando que este se torne fragmentado.

\section{Dificuldades e limites na execução do Projeto Terapêutico}

De acordo com a avaliação dos profissionais dos dois serviços, a execução do projeto terapêutico nem sempre leva aos resultados esperados. A dificuldade de acesso do usuário ao CAPS, decorrentes da condição clínica, do desconhecimento sobre o serviço, da falta de recursos para o transporte, da relutância em aderir ao tratamento, entre outros, interferem no projeto terapêutico. Esses fatores comprometem a manutenção do projeto terapêutico, prejudicando o usuário, além de interferir no trabalho dos profissionais, provocando um desgaste de energia e um sentimento de impotência.

Limites atribuídos ao processo da doença ou à sua gravidade não impedem o trabalho dos profissionais no sentido de evitar a internação.

"A gente tem muito paciente crônico que a gente consegue... manter estável. Por mais que a gente tente conseguir alguma coisa mais do que isso, a gente consegue só isso, que ele não piore que não seja mais internado".

Outros fatores considerados limitantes para o alcance de resultados esperados se referem à não apropriação, por parte do usuário, das atividades propostas, a recusa a comparecer no serviço ou a opção por seguir apenas às prescrições medicamentosas. Outro aspecto apontado foi a dificuldade de recursos materiais para a execução de grupos e oficinas, que compromete a qualidade e a manutenção do projeto terapêutico.

As entrevistas evidenciaram a dificuldade em efetivar os encaminhamentos de usuários para outros serviços e recursos da comunidade, que muitas vezes vem acompanhada da recusa dos próprios usuários em aceitar tais encaminhamentos. Neste aspecto, observou-se que o CAPS II Perdizes consegue realizar parcerias, com a rede de serviços e com a comunidade, e estabelecer a contrareferência com mais facilidade. Já no CAPS II Mandaqui, foi citada a falta de recursos humanos nas Unidades Básicas de Saúde do território e a dificuldade de realização de trabalhos externos ao serviço.

No caso do CAPS II Mandaqui, a transformação de ambulatório de saúde mental para CAPS foi apontada como um fator que interferiu no processo de trabalho dos profissionais, que têm dificuldade em se adaptar às novas proposições. No CAPS II Perdizes, os profissionais parecem conviver melhor com essa situação, provavelmente, por atender muitos usuários no regime não intensivo.

“... aqui era um ambulatório de saúde mental que foi transformado, meio que por decreto, em CAPS, e então as pessoas não tiveram preparo, não tiveram a oportunidade de optar por um CAPS, que é um outro modelo de trabalho...".

O conteúdo das entrevistas mostrou que as mudanças ocorridas em função da transformação dos ambulatórios em CAPS e da municipalização, acompanhadas pelas mudanças de gestão, implicaram em grandes necessidades de adaptação dos profissionais, trouxeram incertezas, comprometeram a dinâmica do trabalho além de interferirem na execução dos projetos terapêuticos:

"Então eu hoje me sinto um pouco confusa (...), dentro do que eu estou fazendo, estou seguindo realmente as diretrizes de CAPS? Estou realmente contribuindo para a melhora do usuário ou não".

"Tem um certo... desânimo também das pessoas que são da prefeitura que são mais antigas (...) tem a loucura própria da equipe que não... tem nada a ver com política de saúde mental, que é uma loucura própria da dinâmica da equipe, e que tem alguns momentos... onde esses conflitos ficam mais graves... Aqui dentro as coisas se esfacelarem mais, não é?... Então acho que todas essas coisas dificultam а ехесис̧а̃o".

As dificuldades e os limites para a execução do projeto terapêutico são, praticamente, semelhantes nos CAPS II Perdizes e CAPS II Mandaqui. Foram citados fatores ligados ao usuário (dificuldade de acesso ao serviço, limites do próprio usuário, abandono do tratamento), ao sistema de saúde (falta de recursos, dificuldade na implantação do sistema de referência e contra-referência), às questões sociais e à equipe multiprofissional (dificuldades de adaptação às mudanças). 
MÂNGIA, E. F. et al. A construção de projetos terapêuticos. Rev. Ter. Ocup. Univ. São Paulo, v. 17, n. 2, p. 87-98, maio/ago., 2006.

Observa-se que, nos dois serviços, a execução do projeto terapêutico, muitas vezes, não leva aos resultados esperados em função das dificuldades e das limitações que os profissionais e o próprio serviço apresentam. Percebese, a existência de conflitos e questionamentos quanto às condições e qualidade do trabalho, ao relacionamento entre a equipe, e ao relacionamento com outras instâncias referentes ao contexto do serviço (comunidade, família, e ao próprio usuário), provocando certo desânimo e frustração por parte dos profissionais.

"As possibilidades de fracasso do programa terapêutico fazem pensar nos limites do serviço, bem como na insistência da doença, vista como persistência de um sinal social por decifrar e, em todo caso, no seu difícil planejamento terapêutico. Todavia, num serviço territorial como o nosso, o fracasso, a presença de soluções impossíveis são a substância do trabalho cotidiano, pois determinam um repensar e um reelaborar da intervenção a partir dos limites evidenciados" (DELL'ACQUA, MEZZINA, 2005, p.192).

A proposta de realização de projetos terapêuticos singularizados provoca conflitos entre as necessidades do usuário e a organização do serviço, pois para gerar respostas operativas adequadas torna-se necessária a flexibilidade da organização do trabalho. As reuniões diárias possibilitam o maior envolvimento da equipe, de modo que qualquer profissional pode participar da discussão sobre a condução dos projetos terapêuticos, da avaliação dos resultados alcançados, e sugerir novas propostas (DELL'ACQUA, MEZZINA, 2005). Acreditamos que os profissionais sempre encontrarão dificuldades e limites na execução do trabalho, porém é importante que consigam identificá-los para, então, planejar novas estratégias de superação.

\section{O funcionamento dos serviços: o projeto CAPS e o projeto terapêutico}

As entrevistas evidenciam que, apesar de pertencerem à mesma modalidade de CAPS, os dois serviços têm um funcionamento diferente. O CAPS é responsável por uma área de abrangência e a conscientização da equipe sobre assumir a responsabilidade pela demanda de seu território, aparece nas entrevistas:

"Eu acho que a gente está chegando no ponto é... ou vai ou racha, ... ou a coisa vai...virar para acontecer de uma maneira em que o profissional vai para o território, vai se responsabilizar pelo território, por ações de saúde no território e não ficar só esperando, naquela postura hospitalocêntrica e ambulatorial, o paciente chegar".

Observa-se que a proposta de trabalho dos CAPS tem sido alterada em função da dificuldade no encaminhamento do usuário para outros equipamentos de saúde.

“(...) não tem para onde encaminhar. (...) a gente não consegue encaminhar para a unidade básica se for o caso...”.

“...hoje não dá pra pensar para reencaminhar, seja porque não tem serviço fortalecido lá, seja porque ele já tem uma referência aqui...”.

“... esse pessoal que já está aqui, que de algum jeito é uma super população... interfere no trabalho que a gente está fazendo com os outros pacientes mais intensivos".

Desse modo, percebe-se que o trabalho de integração entre os diferentes equipamentos na rede de serviços de saúde ainda não está efetivado no Município de São Paulo.

“... a rede básica... está despreparada para receber o paciente que passa por aqui. (...) e a continuidade desse tratamento nem sempre é garantida, (...) teria que ter uma rede mais organizada...".

O objetivo dos CAPS é oferecer atendimento à população de sua área de abrangência, realizando o acompanhamento clínico, e a reinserção social dos usuários pelo acesso ao trabalho, lazer, exercício dos direitos civis e fortalecimento dos laços familiares e comunitários. As diferenças encontradas na organização dos serviços conduziram ao seguinte questionamento: se existe um projeto único para os CAPS por que cada um funciona de um jeito?

A primeira observação que fazemos diz respeito à estrutura física dos serviços. O CAPS II Perdizes está instalado numa casa ampla com quintal, o que favorece o transito do usuário nos diferentes espaços; como consequiência, observa-se a convivência entre as pessoas, a participação delas em conversas, a realização de jogos e de rodas de música. O CAPS II Mandaqui, em contrapartida, mantém a estrutura do antigo ambulatório e essa arquitetura dificulta a implantação de atividades que favoreçam a integração; como resultado, observa-se que o ambiente é silencioso e com poucos usuários no espaço externo.

Foram observadas, também, diferenças no processo de trabalho: no CAPS II Mandaqui a primeira orientação do projeto terapêutico consiste em avaliar a condição do usuário em participar do regime intensivo, chamado grupo de crise, com atividades mais voltadas para os psicóticos, ou do regime semi-intensivo, chamado de grupo de continência, com atividades mais voltadas para os neuróticos graves. A equipe passa por um momento de reformulação devido a 
mudanças de gestão e a redução do número de profissionais, principalmente de psiquiatras. No CAPS II Perdizes os usuários, tanto do regime intensivo e quanto do regime semiintensivo, podem escolher participar das atividades que ocorrem nos períodos em que estão na instituição, ou da convivência.

Os serviços oferecem atividades de acordo com as habilidades dos profissionais. Existe variação entre a oferta de atividades dos serviços e a própria habilidade e característica do profissional que as desenvolve. Por outro lado, os profissionais dos serviços têm desempenhado atividades diferentes da especificidade de sua categoria, mesclando ações conforme as necessidades do usuário e a disponibilidade de outros membros da equipe. Há uma maior distribuição da responsabilidade do cuidado entre os integrantes da equipe. Há também a preocupação dos profissionais em realizar o primeiro atendimento do usuário priorizando a escuta, o acolhimento, apesar de muitos usuários recorrerem ao serviço apenas para obter a medicação. Há um consenso de que o uso da medicação é uma parte do tratamento, mas a sua compreensão varia entre os componentes da equipe, o que pode gerar diferenças nas características de funcionamento do serviço.

Questões sobre os âmbitos de responsabilidade do serviço (usuários, território e suas necessidades, construção da rede de serviços) são importantes nos contextos estudados. O serviço deve se constituir como referência, ter um papel ativo na promoção da saúde mental, não apenas nas situações de crise, mas no contato entre o serviço e o território. Deve equipar-se com "instrumentos e recursos capazes de favorecer o crescimento e a autonomia do paciente, além de defender e implementar o seu poder contratual" (DELL'ACQUA, MEZZINA, 2005, p. 168).

Saraceno (1999) ressalta que um bom serviço deve estar organizado de forma integrada e se ocupar de todos os pacientes que o têm como referência e que dele possam se beneficiar com o tratamento que recebem. Dessa forma, as atividades que o serviço realiza devem priorizar as necessidades e os interesses do usuário, de modo que não se tornem rotineiras, e sim, que tenham um sentido para o usuário. É importante ressaltar que isso requer a atenção da equipe na busca de novas alternativas, para que não haja o abandono do tratamento pelo usuário.

A responsabilidade pela demanda do território não depende apenas do próprio serviço, mas de toda a rede de serviços. Apesar dos obstáculos existentes, o processo de tomada de responsabilidade pode ser construído no cotidiano dos serviços; essa concepção de trabalho implica, portanto, na mudança de relação entre os serviços, as equipes, os usuários, suas famílias e a comunidade.
Outro aspecto que pode diferenciar o funcionamento dos serviços, é o modo como se realiza o encaminhamento dos usuários para outros equipamentos. A dificuldade no cumprimento da proposta de atenção aos usuários pode ser superada com o funcionamento efetivo da rede, o que possibilitaria o encaminhamento de usuários que não necessitam mais dos cuidados oferecidos nos CAPS, mas que precisam continuar o tratamento em outros serviços. Para isso é necessário avaliar a capacidade dos outros serviços em absorverem novos usuários e garantirem a continuidade da atenção.

\section{CONSIDERAÇÕES FINAIS}

Ao término deste estudo, algumas considerações merecem destaque. Os resultados encontrados reforçam que há aspectos que precisam ser considerados na construção de projetos terapêuticos: a necessidade de formalização, a definição inicial sobre o tempo de execução, avaliação e possível reformulação, a mudança da relação com o usuário e a sua participação efetiva em todo o processo.

É necessário também, que os profissionais estabeleçam uma relação de confiança com o usuário, reconheçam as suas necessidades e, periodicamente, avaliem se o projeto terapêutico é dinâmico, flexível e aberto às modificações. Para isso, é importante, perceber seus propósitos, distinguir as dificuldades de cada interação e intervenção, avaliar o seu desempenho, refletir e analisar se as ações estão ajudando o usuário a atingir uma melhor qualidade de vida. Mais do que a superação da crise, o pilar de construção de um projeto terapêutico deve ser a vida.

Muitos problemas poderiam ser superados com a capacitação dos profissionais, que na realidade cotidiana enfrentam enormes dificuldades na tentativa de articular a teoria com a prática. É necessária também, a maior articulação entre as diversas instâncias: a comunidade, os conselhos de saúde, a rede de serviços, a participação mais efetiva dos profissionais no estabelecimento de ações no território.

Consideramos que os profissionais deveriam avaliar periodicamente, se as propostas e metas do projeto dos CAPS estão sendo cumpridas e se os serviços estão conseguindo estabelecer mais parcerias com a rede de serviços.

Levantamos algumas questões com o intuito de refletir a respeito das nossas ações: Afinal, o que deveríamos modificar no contexto dos serviços? Como pensar os novos serviços de forma a não reproduzir uma assistência arraigada na cultura hospitalar? O que fazer com os usuários que não respondem ao projeto terapêutico? Como estabelecer as parcerias e a articulação com a rede de serviços? O que priorizar nos atendimentos realizados: grupos, oficinas, atividades externas? 
MÂNGIA, E. F. et al. A construção de projetos terapêuticos. Rev. Ter. Ocup. Univ. São Paulo, v. 17, n. 2, p. 87-98, maio/ago., 2006.

Este estudo propiciou espaço de reflexão sobre aspectos relevantes de nossa prática profissional e esperamos que possa trazer contribuições para o desafio da construção de novos serviços de saúde mental.

MÂNGIA, E. F.; CASTILHO, J. P. L. V.; DUARTE, V. R. E. The construction of therapeutic projects: professionals' visions in two psychosocial care centers. Rev. Ter. Ocup. Univ. São Paulo, v. 17, n. 2, p. 8798, maio/ago., 2006.

\begin{abstract}
The construction of therapeutic projects was studied from the vision of professionals who work in two Psychosocial Care Center (CAPS) in the city of São Paulo. This theme has central importance to the formulation of strategies, definition of a new assistancial profile and organization of new mental health services. The study scenes had been CAPS II Perdizes and CAPS II Mandaqui, in São Paulo's city. It had been done: documental and bibliographical research, field observation and 8 semi-structured interviews with professionals from different categories; it was tried to apprehend the process of construction and accomplishment of the therapeutic projects destined for users who have severe mental illness, as well as to identify the difficulties and limits pointed out by these professionals with respect to their execution. It had been observed differences in the service structure and on the execution of the therapeutic projects in the two institutions. The difficulties and limits to the therapeutic projects execution were similar in both services.
\end{abstract}

KEY WORDS: Mental health services. Health programs and plans. Professional practice. Occupational therapy.

\title{
REFERÊNCIAS
}

ARANHA e SILVA, A. L.; FONSECA, R. M. G. S. Os nexos entre concepção do processo saúde/doença mental e as tecnologias de cuidado. Rev. Latinoamer. Enferm., v.11, n.6, p. 800-6, 2003.

BARDIN, L. Análise de conteúdo. RJ: Editora 70; 2000.

BRASIL. Ministério da Saúde. Portaria SNAS n. 224, de 29 de janeiro de 1992. Disponível em site: http://www.planalto.gov.br/ ccivil_03/Leis_2001/L10216.htm. Acesso: 10 nov. 2005.

BRASIL. Ministério da Saúde. Portaria SNAS n. 336/GM, de 19 de fevereiro de 2002. Disponível em site: http:// www.planalto.gov.br/ccivil_03/Leis_2001/L10216.htm. Acesso: 11 nov. 2005).

BRASIL. Ministério da Saúde - CAPS - Nova sistemática de cadastramento, funcionamento e registro de dados epidemiológicos - Portarias 336/02 e 189/02. Perguntas \& Respostas (perguntas 01 a 12); Brasília, D. F., 2002a.

CECÍLIO, L. C. O. As necessidades de saúde como conceito estruturante na luta pela integralidade e equidade na atenção em saúde. In: PINHEIRO, R.; MATTO, S R. A. (Orgs.). Os sentidos da integralidade na atenção e no cuidado à saúde. Rio de Janeiro: UERJ, IMS: ABRASCO; 2001.

DELL‘ACQUA, G.; MEZZINA, R. Resposta à crise: estratégia e intencionalidade da intervenção no serviço psiquiátrico territorial. In: AMARANTE, P., (Coord.). Archivos de saúde mental e atenção psicossocial 2. Rio de Janeiro: Nau; 2005, p. 161 - 214.

MALTA, D. C.; CECÍLIO, L. C. O.; MERHY, E. E.; FRANCO, T. B.; JORGE, A. O.; COSTA, M. A. Perspectivas da regulação na saúde suplementar diante dos modelos assistenciais. Ciênc. Saúde Coletiva, v. 9, n. 2, p. 442, 2004.

MÂNGIA, E. F.; SOUZA, D. C.; MATTOS, M. F.; HIDALGO, V. C. Acolhimento: uma postura, uma estratégia. Rev. Ter. Ocup. Univ. São Paulo, v. 13, n. 2, p. 15-21, 2002.

MÂNGIA, E. F. Contribuições da abordagem canadense "Prática de Terapia Ocupacional centrada no cliente" e dos autores da desinstitucionalização italiana para a Terapia Ocupacional em saúde mental. Rev. Ter. Ocup. Univ. São Paulo, v. 13, n.3, p. 127-34, 2002.

MINAYO, M. C. S. et al. Pesquisa social: teoria, método e criatividade. $23^{\mathrm{a}}$ ed. rj: Vozes, 2004.

SARACENO, B.; ASIOLI, F.; TOGNONI, G. Manual de saúde mental. São Paulo: Hucitec; 2001.

SARACENO, B. Desafios dos novos serviços de saúde mental no território. [Apresentado no Seminário sobre Saúde Mental na Escola de Enfermagem da USP; no dia 10 de novembro de 2005].

SARACENO, B. Libertando identidades: da reabilitação psicossocial à cidadania possível. Belo Horizonte: Te Cora / Rio de Janeiro: Instituto Franco Basaglia; 1999, p. 96. 